This article was downloaded by: [HINARI Consortium (T\&F)]

On: 3 August 2009

Access details: Access Details: [subscription number 778614432]

Publisher Routledge

Informa Ltd Registered in England and Wales Registered Number: 1072954 Registered office: Mortimer House, 37-41 Mortimer Street, London W1T 3JH, UK

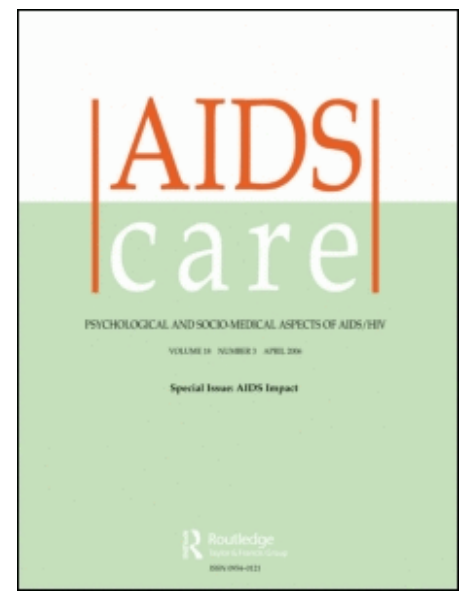

\title{
AIDS Care
}

Publication details, including instructions for authors and subscription information:

http://www.informaworld.com/smpp/title content=t713403300

\section{Development of a Yemeni AIDS Stigma Scale}

Abdallah Badahdah a; Najat Sayem ${ }^{\mathrm{b}}$; Carrie E. Foote ${ }^{\mathrm{c}}$

a Department of Sociology, University of North Dakota, Grand Forks, ND, USA ${ }^{\mathrm{b}}$ Department of Psychology,

Sana'a University, Sana'a, Yemen ' Department of Sociology, Indiana University-Purdue University,

Indianapolis, IN, USA

First Published on: 03 June 2009

To cite this Article Badahdah, Abdallah, Sayem, Najat and Foote, Carrie E.(2009)'Development of a Yemeni AIDS Stigma Scale',AIDS Care,21:6,

To link to this Article: DOI: $10.1080 / 09540120802511927$

URL: http://dx.doi.org/10.1080/09540120802511927

\section{PLEASE SCROLL DOWN FOR ARTICLE}

Full terms and conditions of use: http://www.informaworld.com/terms-and-conditions-of-access.pdf

This article may be used for research, teaching and private study purposes. Any substantial or systematic reproduction, re-distribution, re-selling, loan or sub-licensing, systematic supply or distribution in any form to anyone is expressly forbidden.

The publisher does not give any warranty express or implied or make any representation that the contents will be complete or accurate or up to date. The accuracy of any instructions, formulae and drug doses should be independently verified with primary sources. The publisher shall not be liable for any loss, actions, claims, proceedings, demand or costs or damages whatsoever or howsoever caused arising directly or indirectly in connection with or arising out of the use of this material. 
AIDS Care

2009, 1-6, iFirst article

\title{
Development of a Yemeni AIDS Stigma Scale
}

\author{
Abdallah Badahdah $^{\mathrm{a} *}$, Najat Sayem $^{\mathrm{b}}$ and Carrie E. Foote ${ }^{\mathrm{c}}$ \\ ${ }^{a}$ Department of Sociology, University of North Dakota, Grand Forks, ND, USA; ${ }^{b}$ Department of Psychology, Sana'a University, \\ Sana'a, Yemen; 'Department of Sociology, Indiana University-Purdue University, Indianapolis, IN, USA
}

(Received 25 March 2008; final version received 29 September 2008)

\begin{abstract}
Research on the social and behavioral aspects of AIDS in the Arab world is relatively scarce despite the efforts of a few scholars over the last quarter century. AIDS-related stigma and discrimination are especially important areas that have received little attention. One critical barrier to undertaking such research has been the absence of an Arabic instrument to employ this work. The current study addressed this gap by developing and implementing an Arabic AIDS Stigma Scale that consisted of 10 items. The data were collected from college students at a public university in Yemen. Principle axis factor analysis identified two factors with five items each that explained 35\% of the variance. The availability of the Yemeni AIDS Stigma Scale (YASS) should be a valuable resource for scholars interested in AIDS-related research in Yemen and the rest of the Arab world.
\end{abstract}

Keywords: HIV/AIDS; Yemen; Arab; stigma; scale development

\section{Introduction}

The widespread stigmatization of people with HIV/ AIDS is one of the most devastating aspects of the AIDS epidemic. AIDS stigma almost certainly contributes to the marginalization of its carriers and the spread of HIV. AIDS stigma can do so by causing people to avoid HIV testing and, for those who are HIV-positive, to avoid seeking health care or to minimize adherence to prescribed HIV medications (Fortenberry et al., 2002; Rintamaki, Davis, Skripkauskas, Bennett, \& Wolf, 2006). Furthermore, because of AIDS stigma, many of the afflicted have been subjected to such harsh discriminatory acts as job termination and denial of care. Many have also had restrictions placed on their reproductive and sexual rights (Boonstra, 2006; Cao, Sullivan, Xu, \& $\mathrm{Wu}, 2006)$.

Because of the negative consequences of AIDS stigma, there is a growing recognition that the reduction of such stigma is central to curbing the epidemic around the world (Anderson, Anderson, Salam, \& Wahlstrom, 2004), especially in areas where public attitudes toward people with HIV/AIDS are particularly negative, such as in the Arab countries (WHO, 2002). Yet, one critical barrier to undertaking AIDS related research in the Arab world has been the absence of a well developed scale on AIDS stigma that has been prepared for application to an Arab population.

Scholars recognize a growing need to develop scales in different cultural contexts in order to accurately assess and document the prevalence of AIDS stigma (Van Rie et al., 2008). Others are finding similarities in AIDS stigma across different countries, leading to stigma scales that allow for cross-cultural comparisons (Genberg et al., 2007; Nyblade, 2006; Van Rie et al., 2008). However, none of the numerous AIDS stigma scales that now exist (Nyblade, 2006; Van Brakel, 2006) were developed in an Arab country where Arab norms and the Islamic religion may be linked to AIDS stigma (Roudi-Fahimi, 2007). The current study addressed this gap by developing a short AIDS stigma scale in Arabic and fielding it among college students in Yemen. Findings provide a basis on which to begin to document AIDS stigma and assess stigma reduction strategies in Yemen as well as to develop instruments that can be used in a variety of Arabic countries and for cross cultural comparisons.

\section{Background}

HIV/AIDS prevalence rates remain relatively low in the Middle East and North African (MENA) region. Yet, the region has one of the fastest growing HIV infection rates in the world (UNAIDS, 2007). The overall incidence of infection in the MENA rose over $300 \%$ from 2003 to 2007 , increasing the number of HIV cases from 87,000 to 380,000 . In the Arabic culture, much more so than in most non-Arabic cultures, premarital and extramarital sex, drug use, and homosexuality are considered both sins and crimes. This partly explains the lower HIV rates.

*Corresponding author. Email: abdallah.badahdah@und.nodak.edu

ISSN 0954-0121 print/ISSN 1360-0451 online

(C) 2009 Taylor \& Francis

DOI: $10.1080 / 09540120802511927$

http://www.informaworld.com 


\section{A. Badahdah et al.}

But the same cultural values contribute to the rapid increase of HIV cases because they engender AIDSdenial and strong stigmatization of the afflicted (Roudi-Fahimi, 2007). Yet, despite the rapid rise in infection rates in the MENA region, relatively little AIDS research has taken place.

One of these MENA region countries, Yemen, which is a highly conservative and tribal nation, is located in the southern part of the Arabian peninsula. It is boarded by Oman to the east, Saudi Arabia to the north, the Red Sea to the west and the Arabia sea and the Gulf of Aden to the south. With over 20 million people and high rates of illiteracy, poverty, and unemployment, Yemen remains one of the least developed countries in the world. The nation's per capita gross national product is $\$ 650$ and $42 \%$ of its population lives below the poverty line (WHO, 2005).

The actual number of Yemenis with HIV/AIDS, like the situation in many of the Arab countries, is unknown due to underdeveloped surveillance programs. The Yemeni cultural context, in which premarital and extramarital affairs are punishable crimes and where stigmatization of the afflicted is widespread, further complicates surveillance efforts by eliciting substantial underreporting (Busulwa, 2001). Indeed, AIDS stigma may be especially high among Yemenis as AIDS carriers there have been rejected by their family members, denied employment, denied care, and hassled by the police because of their HIV status (Swanson, 2007). The limited surveillance information that is available suggests a low but growing and hidden epidemic in Yemen. UNAIDS estimates the adult (15-49 years) Yemen prevalence rate at $0.1 \%$, which is 10 times the rate in 1999; the number of HIV-infected people ranges from 4000 to 24,000 (WHO, 2005).

Despite the growing epidemic in Yemen, an extensive literature review reveals that only two HIV/AIDS studies have been conducted in Yemen. One study examined the AIDS related knowledge of 1033 individuals from the city of Sana'a. This study used a version of a measure developed by WHO that was modified to fit a more conservative context (AlSerouri, Takioldin, Oshish, Aldobaibi, \& Abdelmajed, 2002). The second study assessed the attitudes of 2534 Yemenis toward the use of condoms to prevent HIV. The researchers there used a questionnaire that was developed for the study on the basis of items borrowed from international behavioral HIV/ AIDS surveillance surveys (Busulwa et al., 2006). Both studies found that the participants had some basic HIV knowledge, such as knowing HIV is a virus and AIDS is not curable, but that they also had high degrees of misconceptions regarding HIV transmission. Neither study measured AIDS stigma.
Although, HIV rates in Yemen appear low, the epidemic is likely to worsen because of the country's severe economic development challenges and lack of accurate HIV transmission knowledge. These conditions raise risk factors considerably (Lambert, 2007). Equally concerning, the Yemen studies suggest people with AIDS are likely to experience high levels of stigma and discrimination (Al-Serouri et al., 2002; Busulwa, 2001).

Since stigma exacerbates the problem, then one way to reduce the spread of the epidemic is to change negative beliefs toward afflicted groups. Thus, an important step forward in this regard is to understand the depths and nature of stigma toward the HIV/ AIDS afflicted. However, prior to beginning such an investigation, it is critical that researchers develop measurement tools to examine the phenomenon.

Scholars have developed several instruments to measure AIDS stigma (Nyblade, 2006; Van Brakel, 2006). Some of the most widely used scales have been developed in the US (Froman \& Owens, 2001; Froman, Owen, \& Daisy, 1992; Herek, Capitanio, \& Widaman, 2002). These scales may not be culturally appropriate in the developing world (Holzemer \& Uys, 2004). To address this, some scholars have developed AIDS stigma scales in countries as diverse as Thailand, Zimbabwe, South Africa, Brazil, and India (Genberg et al., 2007; Holzemer \& Uys, 2004; Kalichman et al., 2005; Moriya, Gir, \& Hayashida, 1994; Van Rie et al., 2008).

Instruments developed in a wide array of culturally different countries are necessary to enable better comparisons on HIV stigma reduction strategies and their effectiveness (Genberg et al., 2007; Nyblade, 2006). Although, several AIDS Stigma Scales and measures now exist, none of these have been developed and validated in the Arab world. The lack of such instruments has led scholars of AIDS in the Arab world to use self-constructed items and scales developed in non-Arab countries (Al-Serouri et al., 2002; Badahdah, 2005; Gan'czak et al., 2007). The present study aims to fill this gap by developing a short AIDS stigma scale in the Arab country of Yemen.

To this end, we used stigma theory (Goffman, 1963; Link \& Phelan, 2001) and research on AIDS stigma (Anderson et al., 2004; Herek, 1999), to guide our efforts in developing the Yemeni AIDS Stigma Scale (YASS). Goffman (1963), p. 3) defined stigma as "an attribute that is deeply discrediting" which reduces a stigmatized person "from a whole and usual person to a tainted, discounted one". Herek (1999) argues that AIDS is deeply discrediting and lowers the status of the afflicted and those with whom they associate. AIDS related stigma stems from people's 
fear of a deadly disease and their fear of marginalized groups who have been the most frequently afflicted by the disease, particularly intravenous drug users and homosexuals. This fear produces high degrees of prejudice toward the afflicted, blames people with HIV for their illness, and ultimately underlies the harsh treatment and discrimination that some people with AIDS sustain (Anderson et al., 2004).

\section{Methods}

\section{Scale development}

An initial pool of 23 items was generated based on existing sources. First, we studied several conceptualizations of stigma in general and AIDS stigma in particular (Anderson et al., 2004; Goffman, 1963; Link \& Phelan, 2001). Second, we reviewed several existing measures of AIDS stigma (Nyblade, 2006; Van Brakel, 2006).

The initial 23 items were written to reflect the most important aspects of AIDS stigma and contained both positively and negatively worded statements. However, after an extensive review of the items, weighing the relative uniqueness, redundancy and contribution of these items, only 14 of them were chosen. The 14 statements divided into three groups. The first set of items consisted of two items that dealt with the negative stereotypes and beliefs about people with HIV/AIDS (e.g. People with HIV/AIDS are responsible for getting AIDS). The second group of items consisted of four items and was written to gauge the emotional aspect of stigma (e.g. People with AIDS should be shameful of themselves). One of these items was modified to specifically reflect the Yemen context (It is shameful to have people with HIV/AIDS in Yemen). The third group of items was created to reflect the most salient and harmful aspect of AIDS stigma: discrimination, avoidance and rejection. Eight items were written that reflect this domain (e.g. People with AIDS should be quarantined).

All the items were written in English, translated into Arabic, and back-translated into English. The authors reviewed the two translations, discussed the disagreements and resolved inconsistencies utilizing widely recognized techniques developed by Brislin (1970). Respondents used a six-point Likert rating scale that ranged from one (very strongly disagree) to six (very strongly agree).

\section{Construct validity}

Construct validity aims at assessing if a particular measure relates to other variables in a way consistent with theoretically derived hypotheses (Carmines \&
Zeller, 1979). Studies on AIDS stigma have found that people who are knowledgeable about HIV/AIDS tend to hold positive attitudes toward people living with HIV/AIDS (e.g. Herek, Capitanio, \& Widaman, 2002). Therefore, we hypothesized that AIDS knowledge would be inversely correlated with AIDS stigma.

The knowledge of HIV/AIDS index items were adapted from a scale used previously in Saudi Arabia (Badahdah, 2005).Participants were asked whether they know that HIV can live in the human body for years before AIDS symptoms appear; if a mother can transmit HIV to her baby during pregnancy; and if they believe that someone can get HIV by touching someone with HIV/AIDS or by using public phone.Participants reported their knowledge using three response categories: correct, wrong, and do not know.Both wrong and do not know answers were coded as wrong answers. The Cronbach's alpha for the short knowledge index was 0.49 .

\section{Participants}

More than half of the Yemeni population is under the age of 25 (Wolfensohn, 2008). Thus, gauging attitudes toward people with HIV/AIDS of youth approaching adulthood can shed insight on a large part of the community's attitudes toward people with HIV/AIDS. The data were collected from 318 college students attending one of the public universities in Yemen, of whom 157 were males and 161 were females. Previous research has suggested that 300 cases are sufficient for conducing exploratory factor analysis (Comrey, 1992). Participants completed a self-administered questionnaire in Arabic which contained the 14 items, the four AIDS knowledge items, and several demographic background questions including age, marital status, and class status. The age of the participants ranged from 17 to 29 ( $M=21.98$, $\mathrm{SD}=2.30$ ). Eighty-two percent of the participants were single, $16 \%$ were married and five participants did not indicate their marital status. The majority of the participants $(83 \%)$ identified themselves as middle class, $10 \%$ identified themselves as upper class and the rest $(7 \%)$ identified themselves as lower class.

\section{Results}

The 14 items were subjected to a principle axis factor analysis with Promax procedure $(\kappa=4)$, to identify the factor structure of the new scale (Widaman, 1993). The Promax procedure uses a power ( $\kappa)$ of the varimax rotation solution to construct a simple structure that allows for some variation among factors (Russell, 2002). Four factors were extracted with eigenvalues ranging from 4.08 to 1.01 that 


\section{A. Badahdah et al.}

accounted for $37 \%$ of the variance. Examination of the scree plot suggested that two factors should be retained. Items that correlated to 0.40 or higher on one factor and 0.15 or less with the other factor were retained (Kahn, 2006).

Ten items were retained and factor analysis was executed again with the same rotation. Table 1 shows the resulting pattern matrix, which produced two factors that accounted for $35 \%$ of the variance. The first factor (eigenvalue $=3.57$ ) was labeled "rejection" and consisted of five items that dealt with avoidance and aversion and explained $30 \%$ of the variance. The second factor (eigenvalue $=1.23$ ) was labeled "shame and blame" and consisted of five items that measured blame, shame, and judgment and explained $5 \%$ of the variance. The correlation between the two factors was 0.66 .

Several tests indicated that use of the factor analysis was suitable for the current data. Bartlett's test of sphericity was significant $\left(\chi^{2} 731.526, d f=45\right.$, $p=<0.001)$, the determinant of the matrix $(0.11)$ was not zero, all the diagonal values of the anti-image correlation matrix were above the minimum of 0.5 for all the variables and the Kaiser-Meyer-Olkin measure of sampling adequacy was high (0.083).

Table 1. Factor pattern matrix of principle axis factor analysis method of Yemini AIDS Stigma Scale (YASS) items: Promax rotated factor loadings for the two factor solution.

\begin{tabular}{|c|c|c|}
\hline \multirow[b]{2}{*}{ Items } & \multicolumn{2}{|c|}{ Factor } \\
\hline & One & Two \\
\hline \multicolumn{3}{|l|}{ Factor I $(\alpha=0.71)$ "rejection" } \\
\hline $\begin{array}{l}\text { People with AIDS should be fired } \\
\text { from their jobs. }\end{array}$ & 0.72 & 0.00 \\
\hline $\begin{array}{l}\text { It is difficult to sympathize with } \\
\text { people living with HIV/AIDS. }\end{array}$ & 0.45 & 0.10 \\
\hline $\begin{array}{l}\text { People living with HIV/AIDS should be } \\
\text { quarantined. }\end{array}$ & 0.76 & 0.02 \\
\hline $\begin{array}{l}\text { If a friend of mine got AIDS I would } \\
\text { continue being a friend with him } / \text { her. }\end{array}$ & 0.47 & -0.07 \\
\hline $\begin{array}{l}\text { It does not bother me if my } \\
\text { classmate has AIDS. }\end{array}$ & 0.42 & 0.00 \\
\hline \multicolumn{3}{|l|}{ Factor II $(\alpha=0.71)$ "shame and blame" } \\
\hline $\begin{array}{l}\text { People with HIV/AIDS make me } \\
\text { angry. }\end{array}$ & 0.13 & 0.43 \\
\hline $\begin{array}{l}\text { People with HIV/AIDS should be } \\
\text { ashamed of themselves. }\end{array}$ & 0.02 & 0.72 \\
\hline $\begin{array}{l}\text { People with HIV/AIDS are } \\
\text { responsible for getting HIV/AIDS. }\end{array}$ & 0.03 & 0.48 \\
\hline $\begin{array}{l}\text { It is shameful to have people with } \\
\text { HIV/AIDS in Yemen. }\end{array}$ & -0.10 & 0.72 \\
\hline AIDS is a punishment from God. & 0.00 & 0.44 \\
\hline
\end{tabular}

The Cronbach's alphas for the two factors were both 0.71 , which are appropriate for newly developed research instruments (Nunnally, 1978). The alpha coefficient for the entire scale which consists of 10 items was $(\alpha=0.79)$. This result indicates that, although the two subscales are independently reliable, it can also be psychometrically justified to use the overall scale as a single score. The construct validity was assessed by correlating the AIDS Stigma Scale and the AIDS knowledge index. As predicted, participants with greater knowledge about HIV/ AIDS expressed more positive attitudes toward people with HIV/AIDS $(r=0.20, p=<0.001)$.

\section{Discussion}

This study reports the first attempt to develop an Arabic AIDS stigma scale. Using items from scales that were validated in other countries, the items were translated into Arabic and administered to a sample of HIV non-infected college students in Yemen. The YASS comprised 10 items which were developed to gauge AIDS-related stigma in Yemen. The items split into two factors that covered critical manifestations of AIDS stigma: rejection and blame. The rejection factor explained $30 \%$ of the variance and dealt with the most disturbing social aspect of stigma (Link \& Phelan, 2001). It conveyed an attitude of rejection, isolation, and avoidance of people with HIV/AIDS. The second factor was about shame and blame. It was about negative feelings toward people with AIDS, such as anger and shame and the beliefs that people with HIV/AIDS are blameworthy and deserve what they get. This second dimension of AIDS stigma was not surprising given the extreme taboo nature of sex in Arab societies and the fact that sex is the main route through which HIV is transmitted in Yemen. It can also be seen as an antecedent of the attitudes conveyed in the first factor that discrimination, avoidance and support for denigrating public HIVrelated policies are justified.

The YASS is short but it covered several critical aspects of AIDS stigma as outlined by many studies in the AIDS literature (Anderson et al., 2004). For example, the 10 items reported here captured what Herek et al. (2002) identified as the four manifestations of AIDS stigma: negative feelings toward people with AIDS, support for coercive AIDS-related policies, blaming people with AIDS, and avoiding them. In Yemen, these four manifestations of stigma clustered together in two factors.

Other than one item that was specific to Yemen, the scale is not different from other commonly used scales in other countries. This is important, as it may suggest that the social context of AIDS stigma in 
Arab countries may not be that different from nonArab countries. In addition, the development of this scale lends support to recent findings that some of the AIDS stigma scales are useful in multiple cultural settings (Genberg et al., 2007; Van Brakel, 2006). None of these previous studies developed scales in an Arabic context. Thus, this study lends further support to those findings by being able to use such scales in an Arab cultural setting.

Despite the significance of this study in developing an Arabic scale to measure AIDS stigma in Yemen, there are some limitations associated with this endeavor. First, the YASS was developed in a sample of college students who might not have HIV/ AIDS. Thus, the scale might not capture the attitudes of the general public's attitudes toward people with HIV/AIDS in Yemen. In addition, it did not capture the perspective of HIV-infected Yemenis. Researchers, however, can use the items developed in this study as a starting point for the development of a more broadly based scale that includes more measures to capture different dimensions of AIDS stigma. The scale can also be used as a basis on which to develop scales in other Arab countries. Second, because of resource limitations, the present study was not able to conduct a conformity factor analysis to provide further evidence on the suitability of two factor solution.

Eliminating AIDS stigma in Arab countries, as well as in other parts of the world, is essential to slowing the rate of the epidemic and to enabling the afflicted to live lives free of fear, intolerance and discrimination (Anderson et al., 2004; Cheemeh, Montoya, Essien, \& Ogungbade, 2006). Having a tested scale written in Arabic tremendously reduces the problems associated with researchers using variant translations of items. We hope that the availability of this new scale will encourage more research on AIDS in Yemen and the rest of the Arab world as well as enable researchers to include Arab countries in cross-cultural AIDS stigma research.

\section{References}

Al-Serouri, A.W., Takioldin, M., Oshish, H., Aldobaibi, A., \& Abdelmajed, A. (2002). Knowledge, attitudes and beliefs about HIV/AIDS in Sana'a, Yemen. Eastern Mediterranean Health Journal, 8(6), 706-715.

Anderson, M., Anderson, S., Martin, A., Salam, F., \& Wahlstrom, J. (2004). HIV/AIDS anti-stigma initiative: Selected literature: 2000-2004. Washington, DC: Center on AIDS \& Community Health.

Badahdah, A. (2005). Saudi attitudes towards people living with HIV/AIDS. International Journal of STD and AIDS, 16(12), 837-838.
Boonstra, H. (2006). Meeting the sexual and reproductive health needs of people living with HIV. Guttmacher Institute, 6, 1-4.

Brislin, R.W. (1970). Back-translation for cross-cultural research. Journal of Cross-Cultural Psychology, 1, 185216.

Busulwa, R. (2001). HIV/AIDS in Yemen: A summary briefing. London: Changing Minds, Changing Lives.

Busulwa, R., Takiyaddin, M.Y., Azzubeidi, A.A., El Zein El Mousaad, H., Tawillah, J., \& Ziady, H. (2006). Perceptions of the condom as a method of HIV prevention in Yemen. Eastern Mediterranean Health Journal, 12(Suppl. 2), S64-S77.

Cao, X., Sullivan, S.G., Xu, J., \& Wu, Z. (2006). Understanding HIV-related stigma and discrimination in a "blameless" population. AIDS Education and Prevention, 18(6), 518-528.

Carmines, E., \& Zeller, R. (1979). Reliability and validity assessment. Newbury Park, CA: Sage.

Cheemeh, P.E., Montoya, I.D., Essien, E.J., \& Ogungbade, G.O. (2006). HIV/AIDS in the Middle East: A guide to a proactive response. Journal of the Royal Society for the Promotion of Health, 126(4), 165-171.

Comrey, A.L. (1992). A first course in factor analysis. Hillsdale, NJ: Lawrence Erlbaum.

Fortenberry, J.D., McFarlane, M., Bleakley, A., Bull, S., Fishbein, M., Grimley, D.M., et al. (2002). Relationships of stigma and shame to gonorrhea and HIV screening. American Journal of Public Health, 92(3), 378-381.

Froman, R., \& Owens, S. (2001). Measuring attitudes towards persons with AIDS: The AAS-G as an alternate form of the AAS. Scholarly Inquiry for Nursing Pactice, 15, 161-174.

Froman, R., Owen, S., \& Daisy, C. (1992). Development of a measure of attitudes toward persons with AIDS. The Journal of Nursing Scholarship, 24(2), 149-152.

Gan'czak, M., Barss, P., Alfaresi, F., Almazrouei, S., Muraddad, A., \& Al-Maskari, F. (2007). Break the silence: HIV/AIDS knowledge, attitudes, and educational needs among Arab university students in United Arab Emirates. Journal of Adolescent Health, 40(6), e571-e578.

Genberg, B.L., Kawichai, S., Chingono, A., Sendah, M., Chariyalertsak, S., \&Konda, K.A. et al. (2007). Assessing HIV/AIDS stigma and discrimination in developing countries. AIDS and Behavior. Retrieved December 13, 2007, from http://www.springerlink. com/content/d374717030488713/

Goffman, E. (1963). Stigma: Notes on the management of a spoiled identity. Englewoods Cliffs, NJ: Spectrum.

Herek, G.M. (1999). AIDS and stigma. American Behavioral Scientist, 42(7), 1106-1116.

Herek, G.M., Capitanio, J.P., \& Widaman, K.F. (2002). HIV-related stigma and knowledge in the United States: Prevalence and trends, 1991-1999. American Journal of Public Health, 92(3), 371-377.

Holzemer, W.L., \& Uys, L.R. (2004). Managing AIDS stigma. Journal of Social Aspects of HIV/AIDS, l(3), $165-174$. 
Kahn, J.H. (2006). Factor analysis in counseling psychology research, training, and practice: Principles, advances, and applications. The Counseling Psychologist, 34, 684-718.

Kalichman, S.C., Simbayi, L.C., Jooste, S., Toefy, Y., Cain, D., Cherry, C., et al. (2005). Development of a brief scale to measure AIDS-related stigma in South Africa. AIDS and Behavior, 9(2), 135-143.

Lambert, L. (2007). HIV and development challenges in Yemen: which grows fastest? Health Policy and Planning, 22(1), 60-62.

Link, B.G., \& Phelan, J.C. (2001). Conceptualizing stigma. Annual Review of Sociology, 27, 363-385.

Moriya, T.M., Gir, E., \& Hayashida, M. (1994). A scale of attitudes towards AIDS: A psychometric analysis. Rev Lat Am Enfermagem, 2(2), 37-53.

Nunnally, J.C. (1978). Psychometric theory (2nd ed). New York: McGraw-Hill.

Nyblade, L.C. (2006). Measuring HIV stigma: Existing knowledge and gaps. Psychology. Health and Medicine, 11(3), 335-345.

Rintamaki, L.S., Davis, T.C., Skripkauskas, S., Bennett, C.L., \& Wolf, M.S. (2006). Social stigma concerns and HIV medication adherence. AIDS Patient Care and STDS, 20(5), 359-368.

Roudi-Fahimi, F. (2007). Time to intervene: Preventing the spread of HIV/AIDS in the Middle East and North Africa. Washington, DC: Population Reference Bureau.

Russell, D.W. (2002). In search of underlying dimensions: The use (and abuse) of factor analysis. Personality and Social Psychology Bulletin, 28, 1629-1646.
Swanson, D. (2007). Yemen: It's tough living with HIV. In Plus News: Global HIV/AIDS News and Analysis. Retrieved March 9, 2008, from http://www.plusnews. org/PrintReport.aspx?ReportID = 73436

UNAIDS. (2007). AIDS epidemic update. Geneva, Switzerland: World Health Organization.

Van Brakel, W.H. (2006). Measuring health-related stigma - a literature review. Psychology. Health and Medicine, 11(3), 307-334.

Van Rie, A., Sengupta, S., Pungrassami, P., Balthip, Q., Choonuan, S., Kasetjaroen, Y., et al. (2008). Measuring stigma associated with tuberculosis and HIV/AIDS in southern Thailand: Exploratory and confirmatory factor analyses of two new scales. Tropical Medicine Inernational Health, 13(1), 21-30.

WHO. (2002). The context of HIV/AIDS related stigma and discrimination in the Middle East. Geneva, Switzerland: WHO Regional Office for the Eastern Mediterranean.

WHO. (2005). Yemen. In WHO HIV/AIDS Treatment Scale-Up Summary Country Profiles. Retrieved March 9, 2008, from http://www.who.int/hiv/HIVCP_YEM. pdf

Widaman, K.F. (1993). Common factor analysis versus principal component analysis: Differential bias in representing model parameters. Multivariate Behavioral Research, 28, 263-311.

Wolfensohn, J. (2008). Yemen youth voices. Retrieved July 15, 2008, from http://web.worldbank.org/WBSITE/ EXTERNAL/COUNTRIES/MENAEXT/YEMENEX TN/0, contentMDK:20289638 menuPK:541756 page PK:1497618 piPK:217854 theSitePK:310165,00.html 